\title{
ANALISIS FAKTOR PENYEBAB KETERLAMBATAN PENGUMPULAN SASARAN KERJA PEGAWAI ADMINISTRASI KESEHATAN BAGIAN KEPEGAWAIAN DI RUMAH SAKIT UMUM DAERAH Dr. SOETOMO
}

\author{
Siti Mai Syaroh, M. Risya Rizki* \\ *Prodi S1 Administrasi Rumah Sakit \\ STIKES Yayasan Rumah Sakit Dr. Soetomo \\ Email : sitimaysarohstikes@gmail.com
}

\begin{abstract}
ABSTRAK
Awal tahun 2014 sistem penilaian prestasi kinerja pegawai di RSUD Dr. Soetomo dirubah sesuai dengan perintah Peraturan Undang-Undangan Republik Indonesia Nomor 5 Tahun 2014 Tentang Aparatur Negeri Sipil pada pasal 75 dijelaskan bahwa penilaian prestasi kinerja didasarkan pada sistem prestasi dan sistem karier, hal ini menyebabkan persentase keterlambatan pengumpulan sasaran kerja pegawai mengalami peningkatan. Penelitian ini bertujuan untuk Menganalisis faktor penyebab keterlambatan pengumpulan sasaran kerja pegawai administrasi kesehatan bagian kepegawaian di RSUD Dr. Soetomo. Penelitian ini bersifat penelitian deskriptif (deskriptive research). Teknik pengambilan sampel menggunakan teknik non probability sampling yaitu sebanyak 31 pegawai administrasi kesehatan di bagian kepegawaian dan jumlah responden yang didapatkan pada penelitian ini sebanyak 25 pegawai administrasi kesehatan.

Hasil penelitian ditemukan dari indikator penelitian yaitu faktor yang mempengaruhi kepatuhan seseorang (individu) diantaranya pengetahuan, sikap, tindakan dan motivasi pegawai administrasi kesehatan di bagian kepegawaian perlu diperbaiki, karena ada ketidak seimbangan yang akhirnya menyebabkan keterlambatan dalam pengumpulan sasaran kerja pegawai administrasi kesehatan di bagian kepegawaian. RSUD Dr. Soetomo khususnya pada bagian kepegawaian disarankan menyelenggarakan sosialisasi terkait dengan isi dari Peraturan Kepala Badan Kepegawaian Negara Nomor 1 Tahun 2013 Tentang Ketentuan Pelaksanaan Peraturan Pemerintah Nomor 46 Tahun 2011 Tentang Penilaian Prestasi Kerja Pegawai Negeri Sipil guna menambah pengetahuan tenaga administrasi kesahatan di bagian kepegawaian tentang batas waktu pengumpulan sasaran kerja pegawai dan memperlancar proses penyusunan sasaran kerja pegawai dan diharapkan adanya ketegasan pimpinan dalam memberikan penghargaan (reward) dan hukuman (punisment) sesuai dengan standar prosedur operasional penilaian prestasi kerja pegawai yang berlaku terkait ketepatan waktu pengumpulan sasaran kerja prgawai. Selain itu, diharapkan pula keterlibatan pimpinan atas kesulitan yang dialami bawahannya.
\end{abstract}

Kata Kunci : Kepatuhan, Sistem Penilaian Prestasi Kerja PNS

\section{ABSTRACK}

At the beginning of 2014 appraisal performance system of employee performance in the RSUD Dr. Soetomo changed in accordance with the command Act Regulations Invite Republic of Indonesia Number 5 Year 2014 About the Civil Apparatus in Article 75 explained that the appraisal performance system based on achievement and career system, it causes the percentage delay collection target of employee increased. This study aimed to analyze the factors causing delays collection employee target of health administration personnel department RSUD Dr. Soetomo. This research is a descriptive study (descriptive research). 
Sampling technique using non-probability sampling as many as 31 employees of the administrative of health in the civil service and the number of respondents who obtained in this study as many as 25 employees of administrative of health. Based on the research results of the indicators study found that factors affecting adherence person (people) including knowledge, attitudes, actions and motivations. Knowledge, attitudes, actions and motivations of health administrative personnel in the civil service needs to be improved, because there are imbalances that ultimately causes delays in collection of employee target health administrative personnel in the civil service. RSUD Dr. Soetomo especially on the part of personnel advised organize socialization related to the content of the Regulation of the State Employment Agency No. 1 Year 2013 About Conditions of implementation of Government Regulation No. 46 Year 2011 concerning Performance Assessment Work Civil Servants in order to increase knowledge of administrative personnel of health in the civil service on the time limit collection employee work objectives and facilitate the process of preparation of the target employee. In addition, expected that the firmness leader in reward and punisment accordance with the standart operating procedures of performance appraisal of employess that applies to the timeliness of the collection target of the employment. As well, is also expected in the management engagement on the difficulties experianced by subordinates.

Keywords : Compliance, System Performance Appraisal Of Civil Servants

\section{PENDAHULUAN}

Tekanan organisasi sektor publik, khususnya organisasi pemerintah baik pusat dan daerah serta perusahaan milik pemerintah dan organisasi sektor publik lainnya untuk memperbaiki kinerjanya mendorong dibangunnya sistem manajemen organisasi sektor publik yang berbasis kinerja (performance based management). Fokus manajemen berbasis kinerja adalah pengukuran kinerja organisasi sektor publik yang berorientasi pada pengukuran outcome (hasil) bukan lagi sekadar pengukuran input atau output saja. Manajemen berbasis kinerja dilakukan secara berkelanjutan dan berjangka panjang yang meliputi kegiatan penetapan sasaran kinerja strategik, pengukuran kinerja, pengumpulan data kinerja dan pelaporan kinerja. Data kinerja dan pelaporan kinerja memberikan umpan balik (feedback) untuk melakukan perbaikan kinerja (Mahmudi, 2015).

Manajemen berbasis kinerja membutukan alat yang disebut pengukuran kinerja. Pengukuran kinerja digunakan sebagai dasar untuk melakukan penilaian kinerja. Pengukuran kinerja meliputi aktivitas penetapan serangkaian ukuran atau indikator kinerja yang memberikan informasi sehingga memungkinkan bagi unit kerja untuk memonitoring kinerjanya dalam menghasilkan output dan outcome (Mahmudi, 2015).

Berdasarkan Undang-Undang Republik Indonesia Nomor 5 Tahun 2014 Tentang Aparatur Sipil dijelaskan bahwasannya penilaian prestasi kerja pegawai negeri sipil (PNS) adalah suatu proses penilaian secara sistematis yang dilakukan oleh pejabat penilai terhadap sasaran kerja pegawai dan perilaku kerja 
pegawai negeri sipil. Penilaian prestasi kerja pegawai negeri sipil bertujuan untuk menjamin objektivitas pembinaan PNS yang dilakukan berdasarkan sistem prestasi kerja dan sistem karier. PNS wajib menyusun Sasaran Kerja Pegawai (SKP) rencana kerja tahunan dan memuat kegiatan tugas jabatan dan target yang harus dicapai dalam kurun waktu penilaian yang bersifat nyata dan dapat diukur. Oleh karena itu, dalam teknis penyusunan penilaian prestasi kerja pengetahuan dan kepatuhan pegawai memegang peranan yang sangat penting karena penilaian sasaran kinerja pegawai dilakukan dengan cara membandingkan antara realisasi kerja dengan target dan dalam penilaian perilaku kerja sendiri meliputi aspek orientasi pelayanan, integritas, komitmen, disiplin, kerja sama dan kepemimpinan.

Sistem penilaian prestasi kinerja pegawai RSUD Dr. Soetomo sebelumnya diterapkan dalam bentuk DP3 (Daftar Penilaian Pelaksanaan Pekerjaan) dimana penilaian prestasi kinerja hanya dilihat dari aspek perilaku pegawai, namun sejak diberlakukan Undang-Undang Republik Indonesia Nomor 5 Tahun 2014 Tentang Aparatur negeri Sipil pada pasal 75 dijelaskan bahwa penilaian prestasi kinerja didasarkan pada sistem prestasi dan sistem karier.
Penilaian kinerja sendiri diatur dalam Peraturan Pemerintah No. 46 Tahun 2011 Tentang Penilaian Prestasi Kerja Pegawai Negeri Sipil, dijelaskan pada pasal 4 bahwasannya penilaian prestasi kerja terdiri atas unsur SKP dan perilaku kerja. Setiap pegawai wajib menyusun SKP berdasarkan rencana kerja tahunan instansi (pasal 5 ayat 1) dan SKP memuat kegiatan tugas jabatan dan target yang harus dicapai dalam kurun waktu penilaian yang bersifat nyata dan dapat diukur (pasal 5 ayat 2). Batas waktu pengumpulan SKP ditetapkan setiap tahun pada bulan Januari (pasal 5 ayat 5). Oleh karena itu mulai tahun 2014 sistem penilaian prestasi kinerja pegawai di RSUD Dr. Soetomo dirubah sesuai dengan peraturan perundang-undangan yang berlaku.

Pada awal berlakunya sistem SKP maka diadakan seminar internal dengan mengundang perwakilan pada masing masing bidang, bagian maupun instalasi. Diharapkan dengan adanya seminar internal tersebut dapat membantu pegawai dalam menyusun SKP, namun selama 2 (dua) tahun terakhir persentase keterlambatan pengumpulan berkas penilaian prestasi kerja atau biasa disebut dengan SKP masih tergolong tinggi. Berikut adalah persentase keterlambatan pengumpulan SKP PNS akhir tahun 2014 s/d Bulan Januari 2015: 
Tabel 1.1 Persentase Pengumpulan Sasaran Kinerja Pegawai Negeri Sipil (PNS) Bulan Desember 2014 s/d Bulan Januari 2015

\begin{tabular}{|c|c|c|c|c|}
\hline N & \multirow{2}{*}{ Gol } & \multirow{2}{*}{$\begin{array}{c}\text { Jum. } \\
\text { o }\end{array}$} & T. 2014 & T. \\
\cline { 3 - 5 } & & & $\mathbf{( \% )}$ & $\mathbf{2 0 1 5}$ \\
\hline 1 & P1 & 346 & 42 & 72 \\
\hline 2 & P2 & 906 & 36 & 51 \\
\hline 3 & P3 & 306 & 40 & 57 \\
\hline $\mathbf{4}$ & P4 & $\mathbf{1 1 8 6}$ & $\mathbf{4 4}$ & $\mathbf{5 2}$ \\
\hline 5. & P5 & 40 & 40 & 30 \\
\hline
\end{tabular}

Keterangan :

P1 : Dokter

P2 : Perawat

P3 : Pegawai kesehatan lainnya

P4 : Pegawai Administrasi kesehatan

P5 : Pejabat Struktural

Pada tabel 1.1 diketahui pada akhir tahun 2014 sampai dengan bulan januari tahun 2015 pegawai administrasi kesehatan yang belum mengumpulkan SKP sebanyak 44\% dari total jumlah pegawai administrasi kesehatan PNS dan pada akhir tahun 2015 sampai dengan bulan april 2016 pegawai administrasi kesehatan PNS yang belum mengumpulkan SKP sebanyak 52\%. Perihal tersebut menggambarkan adanya faktor ketidak patuhan pegawai khususnya pada pegawai administrasi kesehatan (P4) dalam batas waktu pengumpulan SKP yang telah ditentukan..

\section{Menurut Notoadmodjo}

kepatuhan adalah suatu perubahan perilaku dari yang tidak menaati peraturan ke perilaku menaati aturan dan faktor yang mempengaruhi kepatuhan adalah pengetahuan, sikap, tindakan dan motivasi.

\section{METODE}

Jenis penelitian ini adalah penelitian deskriptif (deskriptive research) serta ditinjau dari sifat permasalah dari penelitian termasuk dalam penelitian kausal-komparatif (sebab akibat). Penelitian dilakukan mulai Bulan Mei 2016 hingga Bulan Juli 2016 dengan objek penelitian di Bagian Kepegawaian RSUD Dr. Soetomo.

Adapun populasi dalam penelitian ini adalah adalah pegawai administrasi kesehatan di bagian kepegawaian RSUD Dr. Soetomo sebanyak 31 pegawai. Pengambilan sampel menggunakan tenik Non Probability Sampling. Namun sampel yang digunakan dalam penelitian sebanyak 25 pegawai administrasi kesehatan di bagian kepegawaian dikarenakan 6 pegawai administrasi kesehatan tidak bersedia menjadi responden.

Penelitian ini menggunakan kuesioner tertutup sebagai instrument penelitian untuk mengumpulkan data primer. Teknik analisis data dimulai dengan menelaah seluruh data yang telah diperoleh menggunakan skala likert dan analisis hukum pareto 80/20. Dalam tahap analisis data dihasilkan persentase dari setiap faktor individu (pegawai) yang menjadi indikator faktor penyebab keterlambatan pengumpulan SKP pegawai 
administrasi kesehatan di bagian kepegawaian RSUD Dr. Soetomo.

\section{HASIL PENELITIAN}

Hasil akhir dari nilai yang diperoleh dari setiap variabel yang diukur menggunakan skala likert adalah sebagai berikut:

Tabel 1.2 Hasil Analisis Data Menggunakan Skala Likert Tahun 2016

\begin{tabular}{|c|l|c|}
\hline No & \multicolumn{1}{|c|}{ Indikator } & (\%) \\
\hline 1 & Pengetahuan & 73 \\
\hline 2 & Sikap & 60 \\
\hline 3 & Tindakan & 54 \\
\hline 4 & Motivasi & 82 \\
\hline
\end{tabular}

Berdasarkan tabel 1.2 diketahui penilaian pengetahuan pegawai administrasi kesehatan terkait dengan teknis penyusunan SKP memperoleh hasil 73\% masuk dalam kriteria "baik". Untuk penilaian sikap pegawai administrasi kesehatan terkait dengan kepercayaan terhadap sistem penilaian prestasi kerja maka didapatkan $60 \%$ masuk dalam kriteria "baik”. Sedangkan penilaian tindakan tena pegawai administrasi kesehatan terkait dengan ketepatan waktu pengumpulan SKP maka didapatkan 54\% masuk dalam kriteria "baik” serta penilaian motivasi responden terkait dengan sistem penilaian SKP maka didapatkan 82\% masuk dalam kriteria "sangat baik".
Hasil akhir dari nilai yang diperoleh dari setiap variabel yang diukur menggunakan hukum pareto 80/20:

1. Pengetahuan

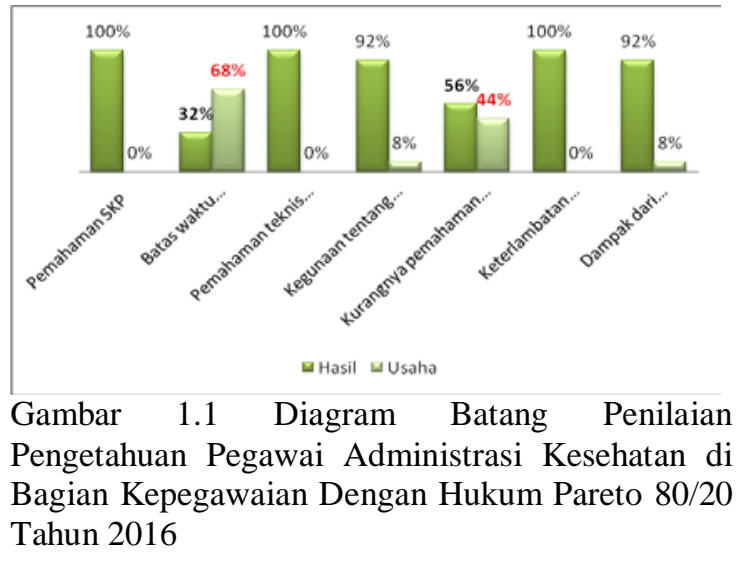

Berdasarkan gambar 1.1 diketahui pengetahuan pegawai administrasi kesehatan di bagian kepegawaian yang berpotensi menjadi isue yang perlu diselesaikan karena nilai frekuensi >20\% adalah kurangnya pengetahuan terkait batas waktu pengumpulan SKP dengan frekuesi $68 \%$ dan pemahaman teknis pengisian SKP dengan frekuensi 44\%.

2. Sikap

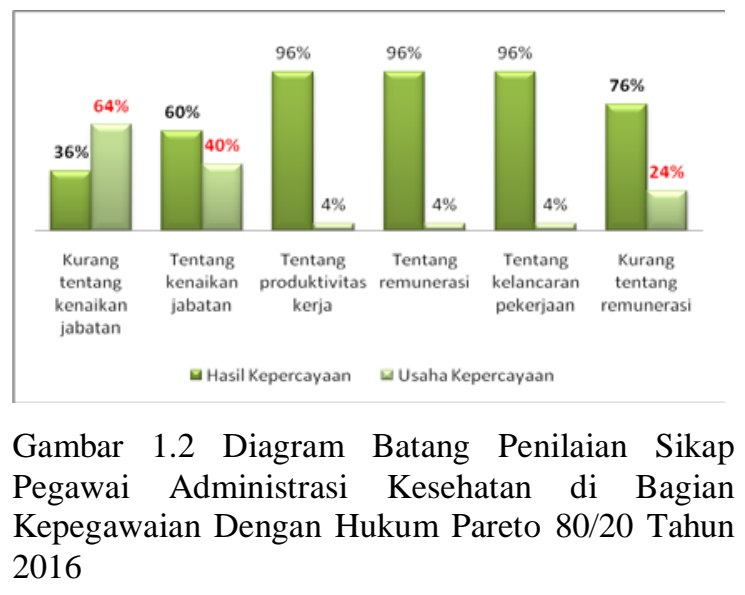

Berdasarkan gambar 1.2 diketahui sikap pegawai administrasi kesehatan di 
bagian kepegawaian yang berpotensi menjadi isue yang perlu diselesaikan karena nilai frekuensi $>20 \%$ adalah tentang kepercayaan akan manfaat dari adanya penilaian prestasi kerja pegawai yang berdampak pada kenaikan jabatan dengan frekuensi 40\%, kurangnya kepercayaan akan manfaat dari adanya penilaian prestasi kerja pegawai yang berdampak pada kenaikan jabatan dengan frekuensi $64 \%$ dan pada remunerasi dengan frekuensi $24 \%$.

\section{Tindakan}

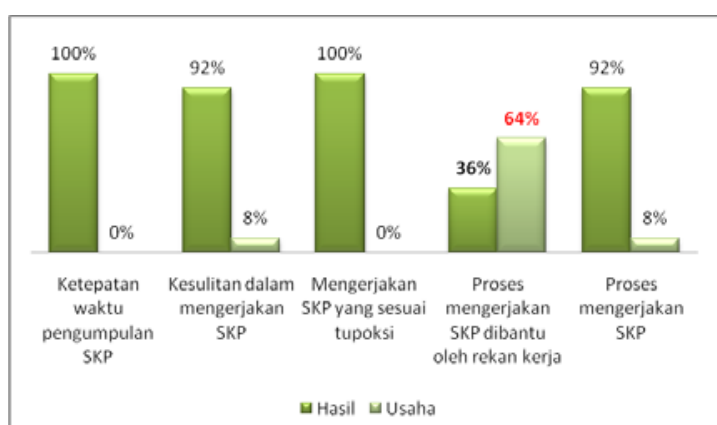

Gambar 1.3 Diagram Batang Penilaian Tindakan Pegawai Administrasi Kesehatan di Bagian Kepegawaian Dengan Hukum Pareto 80/20 Tahun 2016

Berdasarkan gambar 1.3 diketahui tindakan pegawai administrasi kesehatan di bagian kepegawaian yang berpotensi menjadi masalah menjadi isue yang perlu diselesaikan karena nilai frekuensi $>20 \%$ adalah proses mengerjakan SKP yang dibantu oleh rekan kerja dengan frekuensi $64 \%$.
4. Motivasi

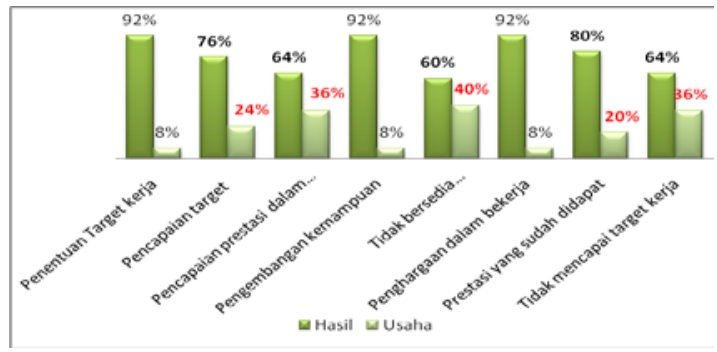

Gambar 1.4 Diagram Batang Penilaian Motivasi Pegawai Administrasi Kesehatan di Bagian Kepegawaian Dengan Hukum Pareto 80/20 Tahun 2016

Berdasarkan gambar 1.4 diketahui motivasi pegawai administrasi kesehatan di kepegawaian yang berpotensi menjadi isue yang perlu diselesaikan karena nilai frekuensi $>20 \%$ adalah dalam perihal pencapaian target dengan frekuensi $24 \%$, pencapaian prestasi dalam bekerja dengan frekuensi 36\%, tidak bersedia melaksanakan tugas tambahan dengan frekuensi 40\%, prestasi yang sudah didapat dengan frekuensi 20\% dan tidak mencapai target kerja dengan frekuensi 36\%.

\section{PEMBAHASAN}

Berdasarkan hasil penelitian tersebut maka pembahasan setiap variabel adalah menurut teori Notoadmodjo (2003) faktorfaktor yang mempengaruhi kepatuhan diantaranya adalah pengetahuan, sikap, tindakan dan motivasi. Dimana dalam setiap faktor yang menjadi indikator dalam penelitian saling terkait. Bila salah satu faktor dinilai kurang memberikan konstribusi maka secara langsung hal tersebut akan menjadi penghambat dalam pencapaian tujuan. Berikut pembahasan 
terkait dengan hasil penelitian tentang penyebab keterlambatan pengumpulan sasaran kerja pegawai (SKP) administrasi kesehatan di bagian kepegawaian:

1. Pengetahuan

Berdasarkan hasil penelitian menggunakan skala likert diketahui pengetahuan pegawai administrasi kesehatan terkait dengan teknis penyusunan SKP secara keseluruhan mendapatkan nilai 73\% dimana dalam penentuan kelas interval tersebut masuk dalam kriteria "baik”. Namun berdasarkan hasil penelitian menggunakan hukum pareto 80/20 dimana setiap pertanyaan dalam kuesioner di frekuensikan satu per satu maka diketahui bahwa pengetahuan pegawai administrasi kesehatan di bagian kepegawaian yang berpotensi menjadi isue yang perlu diselesaikan karena nilai frekuensi $>20 \%$ adalah kurangnya pengetahuan terkait batas waktu pengumpulan SKP dengan frekuesi $68 \%$ dan pemahaman teknis pengisian SKP dengan frekuensi 44\%, maka dapat disimpulkan bahwa pegawai administrasi kesehatan di kepegawaian kurang paham tentang sistem penilaian prestasi kerja yang telah diberlakukan sejak tahun bulan januari 2014 di RSUD Dr. Soetomo. Hal tersebut juga didukung dalam teori
Notoadmodjo (2003) tentang faktorfaktor yang mempengaruhi kepatuhan yang menjadi faktor utamanya adalah pengetahuan. Teori tersebut menjelaskan bahwa pengetahuan merupakan hasil "tahu dan paham" setelah seseorang melakukan penginderaan terhadap suatu objek tertentu. Dalam konteks teknis penyusunan SKP penginderaan yang dimaksud adalah penglihatan dan pendengaran yang memungkinkan seseorang dapat memecahkan masalah yang dihadapinya. Kesimpulannya adalah karena kurangnya pengetahuan pegawai administrasi kesehatan terkait batas waktu pengumpulan SKP dan pemahaman teknis pengisian SKP menjadi faktor penyebab keterlambatan pengumpulan SKP.

2. Sikap

Berdasarkan hasil penelitian menggunakan skala likert diketahui sikap responden terkait dengan kepercayaan responden terhadap sistem penilaian SKP maka didapatkan 60\% dimana dalam penentuan kelas interval tersebut masuk dalam kriteria "baik". Namun berdasarkan hasil penelitian menggunakan hukum pareto 80/20 dimana setiap pertanyaan dalam kuesioner di frekuensikan satu per satu maka diketahui bahwa sikap pegawai 
administrasi kesehatan di bagian kepegawaian yang berpotensi menjadi isue yang perlu diselesaikan karena nilai frekuensi $>20 \%$ adalah tentang kepercayaan akan manfaat dari adanya penilaian prestasi kerja pegawai yang berdampak pada kenaikan jabatan dengan frekuensi 40\%, kurangnya kepercayaan akan manfaat dari adanya penilaian prestasi kerja pegawai yang berdampak pada kenaikan jabatan dengan frekuensi $64 \%$ dan pada remunerasi dengan frekuensi $24 \%$.

Hasil dari indikator sikap tersebut merupakan cerminan dari kurangnya pengetahuan pegawai administrasi kesehatan di bagian kepegawaian dan hal tersebut sesuai dengan teori Notoadmodjo (2003) bahwa peranan penting dalam penentuan sikap adalah pengetahuan berfikir, keyakinan dan emosi. Selain itu dijelaskan pula dalam Undang-Undang Republik Indonesia Nomor 5 Tahun 2014 Tentang Aparatur Sipil Negara pada pasal 77 ayat (5) dijelaskan bahwasannya hasil penilaian kinerja PNS digunakan untuk menjamin objektivitas dalam pengembangan PNS, dan dijadikan sebagai persyaratan dalam pengangkatan jabatan dan kenaikan pangkat, pemberian tunjangan, sanksi, mutasi, dan promosi serta untuk mengikuti pendidikan dan pelatihan dan bagi PNS yang penilaian kinerjanya tidak mencapai target kinerja dikenakan sanksi administrasi sampai dengan pemberhentian sesuai dengan ketentuan peraturan perundangundangan (pasal 77 ayat 6).

Disimpulkan dalam pembahasan sebelum dijelaskan bahwa kurang pengetahuan pegawai administrasi kesehatan, maka secara tidak langsung penentuan sikap pegawai administrasi kesehatan akan terbangun dengan sendirinya tergantung objek atau hal yang telah diketahui dan diyakini akan menguntungkan pegawai administrasi kesehatan di bagian kepegawaian.

3. Tindakan

Berdasarkan hasil penelitian menggunakan skala likert diketahui tindakan pegawai administrasi kesehatan terkait dengan ketepatan waktu pengumpulan SKP maka didapatkan 54\% dimana dalam penentuan kelas interval tersebut masuk dalam kriteria "baik”. Namun berdasarkan hasil penelitian menggunakan hukum pareto 80/20 dimana setiap pertanyaan dalam kuesioner di frekuensikan satu per satu maka diketahui bahwa tindakan pegawai administrasi kesehatan di bagian kepegawaian yang berpotensi menjadi isue yang perlu diselesaikan karena nilai frekuensi $>20 \%$ adalah proses mengerjakan SKP yang dibantu 
oleh rekan kerja dengan frekuensi 64\%.

Hal tersebut sesuai dengan teori Notoadmodjo (2003) dijelaskan tentang yang dimaksud dengan tindakan adalah realisasi dari pengetahuan dan sikap seseorang yang menjadi suatu perbuatan nyata yang dapat diamati dan dilihat oleh orang lain. Kesimpulannya adalah pegawai administrasi telah merealisasikan pengetahuan serta sikap yang telah diketahui tentang sistem penilaian prestasi kerja yang telah diberlakukan meskipun perlu dibantu oleh rekan kerja. Namun jika hal tersebut tidak segera diatasi maka akan menjadi kebiasaan buruk bagi pegawai administrasi kesehatan di bagian kepegawaian yaitu membebankan rekan kerja bagi pegawai administrasi kesehatan lainnya.

4. Motivasi

Berdasarkan hasil penelitian menggunakan skala likert diketahui motivasi responden terkait dengan sistem penilaian SKP maka didapatkan 82\% dimana dalam penentuan kelas interval tersebut masuk dalam kriteria “sangat baik”. Namun berdasarkan hasil penelitian menggunakan hukum pareto 80/20 dimana setiap pertanyaan dalam kuesioner di frekuensikan satu per satu maka diketahui bahwa motivasi pegawai administrasi kesehatan di kepegawaian yang berpotensi menjadi isue yang perlu diselesaikan karena nilai frekuensi $>20 \%$ adalah dalam perihal pencapaian target dengan frekuensi 24\%, pencapaian prestasi dalam bekerja dengan frekuensi 36\%, tidak bersedia melaksanakan tugas tambahan dengan frekuensi 40\%, prestasi yang sudah didapat dengan frekuensi $20 \%$ dan tidak mencapai target kerja dengan frekuensi 36\%. Hal tersebut harus segera diselesaikan agar tidak berdampak lebih besar terhadap kinerja pegawai administrasi di bagian kepegawaian. Hal tersebut sesuai dengan Munandar (2006) mendefinisikan motivasi adalah suatu proses dimana kebutuhan akan mendorong seseorang untuk melakukan serangkaian kegiatan agar tujuannya tercapai serta menurut Gibson James L, dkk (1996) dalam dimensi motivator terdapat serangkaian kondisi instrinsik/ faktor motivator yang dapat menghasilkan hasil kinerja ysng yang baik seperti, prestasi kerja yang berhubungan dengan usaha yang dilakukan seseorang untuk mencapai prestasi kerja optimal serta tanggung jawab yang berhubungan dengan otoritas pada karyawan. Dalam konteks ini adalah tanggung jawab dalam pencapai target yang telah ditentukan 
dan pelaksanaan tugas tambahan dari pimpinan di bidang kepegawaian yang telah menjadi tugas pokok dan fungsi sebagai pegawai administrasi kesehatan. Kesimpulannya adalah kurangnya motivasi pegawai administrasi kesehatan di bagian kepegawaian disebabkan karena kurangnya rasa tanggung jawab sehingga mempengaruhi hasil kinerjanya.

\section{SIMPULAN}

Kesimpulan hasil penelitian yang diajukan dalam penelitian ini mengacu pada tujuan khusus penelitian dan pembahasan pada bab sebelumnya adalah sebagai berikut:

1. Disimpulkan bahwa pengetahuan pegawai administrasi kesehatan di bagian kepegawaian tahu dan paham akan kegunaan dan dampak adanya penilaian prestasi kerja yang telah diberlakukan sejak tahun bulan januari 2014 di RSUD Dr. Soetomo. Namun dalam analisis menggunakan prinsip hukum pareto 80/20 diketahui bahwa pegawai administrasi kesehatan di bagian kepegawaian kurang paham tentang teknis pengisian SKP dan batas waktu pengumpulan SKP.

2. Disimpulkan bahwa sikap pegawai administrasi kesehatan di bagian kepegawaian yang dinilai dari sisi kepercayaan dari adanya penilaian prestasi kerja yang berdampak pada kelancaran kerja dan produktivitas kerja pegawai dinilai baik. Namun dalam analisis prinsip hukum pareto 80/20 diketahui bahwa kepercayaan pegawai administrasi kesehatan dibagian kepegawaian kurang tentang ketepatan waktu pengumpulan SKP berdampak pada kenaikan jabatan dan remunerasi.

3. Disimpulkan bahwa pegawai administrasi di bagian kepegawaian telah bertindak dan merealisasikan pengetahuan serta sikap yang telah diketahui tentang sistem penilaian prestasi kerja guna proses mengerjakan SKP, namun dalam analisis prinsip hukum pareto 80/20 diketahui bahwa proses pengerjaan SKP dibantu oleh rekan kerja. Jika hal tersebut tidak segera diatasi maka akan menjadi kebiasaan buruk bagi pegawai administrasi kesehatan di bagian kepegawaian yaitu membebankan rekan kerja bagi pegawai administrasi kesehatan lainnya.

4. Disimpulkan bahwa motivasi pegawai administrasi kesehatan di bagian kepegawaian dalam penentuan target kerja, pengembangan kemampuan, penghargaan hasil kerja dinilai baik. Namun dalam analisis prinsip hukum pareto 80/20 diketahui bahwa motivasi pegawai administrasi kesehatan dalam pencapaian target kerja dan prestasi 
kerja dinilai kurang termotivasi. Selain itu ketidak bersediaan pegawai dalam melaksanakan tugas tambahan dari pimpinan juga kurang. Hal tersebut disebabkan karena kurangnya rasa tanggung jawab sehingga mempengaruhi hasil kinerjanya.

\section{SARAN}

Berdasarkan kesimpulan diatas, untuk meningkatkan pengetahuan, sikap, tindakan dan motivasi ten pegawai aga administrasi kesehatan di bagian kepegawaian peneliti menyarankan:

1. Agar instansi RSUD Dr. Soetomo khususnya pada bagian kepegawaian guna menyelenggarakan sosialisasi/ seminar internal terkait dengan isi dari Peraturan Kepala Badan Kepegawaian Negara Nomor 1 Tahun 2013 Tentang Ketentuan Pelaksanaan Peraturan Pemerintah Nomor 46 Tahun 2011 Tentang Penilaian Prestasi Kerja Pegawai Negeri Sipil yang menjadi pedoman dalam teknis penyusunan SKP.

2. Diharapkan adanya ketegasan pimpinan dalam memberikan penghargaan (reward) dan hukuman (punisment) sesuai dengan SPO penilaian prestasi kerja pegawai yang berlaku terkait ketepatan waktu pengumpulan SKP. Selain itu, diharapkan pula keterlibatan pimpinan atas kesulitan yang dialami bawahannya.

\section{DAFTAR PUSTAKA}

Atmaja, V, M, 2005. Analisis Pengendalian Kualitas Bagian Finishing Dengan Diagram Pareto Dan Fishbone Pada CV. Teknika Jaya Batur Ceper Klaten. Tugas Akhir. Program Studi D3 Manajemen Industri, Fakultas Ekonomi Universitas Sebelas Maret Surakarta.

Data Persentase Pengumpulan Sasaran Kinerja Pegawai Negeri Sipil (PNS) Akhir Tahun 2014 s/d Bulan Januari 2015. RSUD Dr. Soetomo Provinsi Jawa Timur. Surabaya.

Data Sumberdaya Manusia RSUD Dr. Soetomo Per 31 Mei Tahun 2016. RSUD Dr. Soetomo Provinsi Jawa Timur. Surabaya.

Gibson, James L., John M Ivancevich dan James H Donelly., 1996. Organisasi, Perilaku, Struktur dan Proses, edisi 8. Alih bahasa: Nunuk Adiarni Binaputra Aksara, Jakarta.

Kusumastuti, D, 2014. Hubungan Pengetahuan Dengan Kepatuhan Diet Hipertensi Pada Lansia Yang Mengalami Hipertensi di Panti Wredha Dharma Bakti Kasih Surakarta. Skripsi. Program Studi S1 Keperawatan, Sekolah Tinggi Ilmu Kesehatan Kusuma Husada Surakarta.

Machfoedz, I, 2008. Metodologi Bidang Kesehatan, Keperawatan, Kebidanan, Kedokteran. Yogyakarta: Fitramaya.

Mahmudi, 2015. Manajemen Kinerja Sektor Publik Edisi Ketiga. Yogyakarta: Unit Penerbit dan Percetakan Sekolah Tinggi Ilmu Manajemen YKPN.

Marwansyah, 2010. Manajemen Sumber Daya Manusia Edisi Kedua. Bandung: Alfabeta. 
Nugroho, F, 2012. Pengaruh Motivasi Kerja, Disiplin Kerja dan Pengalaman Kerja Terhadap Produktivitas Kerja Pada Karyawan Pada Industri Kerajinan Topeng di Dusun Bobung, Putat, Patuk, Gunung Kidul. Skripsi. Program Studi Pendidikan Ekonomi, Universitas Negeri Yogyakarta Fakultas Ekonomi.

Peraturan Kepala Badan Kepegawaian Negara Republik Indonesia. 2013. Ketentuan Pelaksanaan Peraturan Pemerintah Nomor 46 Tahun 2011 Tentang Penilaian Prestasi Kerja Pegawai Negeri Sipil. Jakarta: Presiden Republik Indonesia.

Peraturan Pemerintah Republik Indonesia. 2011. Penilaian Prestasi Kerja Pegawai Negeri Sipil. Jakarta: Presiden Republik Indonesia.

Sapoetra, A, N, 2015. Cara Menghitung Kuesioner Skala Likert. http://naufansapoetra.blogspot.co.id/ 2015/11. (diakses 02 Juni 2016)

Sedarmayanti, 2010. Manajemen Sumber Daya Manusia Reformasi Birokrasi dan Manajemen Pegawai Negeri Sipil. Bandung: PT. Refika Aditama.

Soekidjo, N, 2003. Pendidikan dan Perilaku Kesehatan. Jakarta: Rineka Cipta.

Supriyanto S, Djohan A, J, 2011. Metodologi Riset Bisnis dan Kesehatan. Banjarmasin: PT Grafika Wangi Kalimantan.

Suryabatra, S, 2011. Metodologi Penelitian Ed. 1. Jakarta: Rajawali Pers. 